\title{
Fuzzy Logic Controlled Dual Active Bridge Series Resonant Converter for DC Smart Grid Application
}

\author{
Thabit Salim Nassor, Atsushi Yona and Tomonobu Senjyu \\ Graduate School of Engineering and Science, University of the Ryukyus, Okinawa 903-0213, Japan
}

Received: May 25, 2015 / Accepted: July 01, 2015 / Published: August 31, 2015.

\begin{abstract}
Over the last few years, smart grids have become a topic of intensive research, development and deployment across the world. This is due to the fact that, through the smart grid, stable and reliable power systems can be achieved. This paper presents a fuzzy logic control for dual active bridge series resonant converters for DC smart grid application. The DC smart grid consists of wind turbine and photovoltaic generators, controllable and DC loads, and power converters. The proposed control method has been applied to the controllable load's and the grid side's dual active bridge series resonant converters for attaining control of the power system. It has been used for management of controllable load's state of charge, DC feeder's voltage stability during the loads and power variations from wind energy and photovoltaic generation and power flow management between the grid side and the DC smart grid. The effectiveness of the proposed DC smart grid operation has been verified by simulation results obtained by using MATLAB ${ }^{\circledR}$ and PLECS ${ }^{\circledR}$ cards.
\end{abstract}

Key words: DC smart grid, dual active bridge series resonant converter, wind turbine, controllable loads, photovoltaic.

\section{Introduction}

For more than five decades, the power system has heavily depended on fossil fuels, including oil, coal and natural gas, as energy sources. These fossil fuels are nonrenewable and the reserves on the earth are being consumed rapidly. Also exhaust generated from these resources is associated with the environmental destruction such as global warming and pollution [1]. Therefore, in response to these challenges, global attention has been focused on finding alternative energy resources that can sustain long-term industry development. Currently, the identified and implemented RES (renewable energy sources) include wind, hydro, solar, tidal, geothermal and waste energy. These resources are also called green energy because they do not release carbon dioxide $\left(\mathrm{CO}_{2}\right)$ into the atmosphere during electric energy generation and are abundant in nature. These RES are important

Corresponding author: Thabit Salim Nassor, Ph.D. student, research fields: smart grid, power system control, intelligent energy management, power electronics and renewable energy. E-mail: nassor2@hotmail.com. substitutes of fossil fuels for their exploitation durability and environmental friendliness. In fact, this situation has brought about many research studies and deployment across the world for effective methods to harness the RES.

The SG (smart grid) is a re-working of electricity infrastructures-encompassing technology, policy, and business models, which is under way globally [2]. The smart grid architecture would encompass but is not limited to distribution automation/management systems, an advanced metering infrastructure, data communication, and intelligent devices and tools for monitoring, control and optimization. By engaging in the smart grid, several challenges associated with current power and energy systems can be addressed. These include: greenhouse gas emissions and climate change, reliability, economic and energy security as explained in Ref. [2].

For better operation of electrical power systems which incorporate diversified RES, the smart grid is a critical system that determines the effectiveness and efficiency of these systems. It offers a variety of 
advantages over the current systems in terms of digitalization, flexibility, intelligence, resilience, sustainability and customization [3].

The DC grid has the following advantages compared to an $\mathrm{AC}$ power distribution system: (1) Each power generator connected to the DC grid can easily be used cooperatively because the DC grid controls only the DC bus voltage; (2) when the AC grid experiences abnormal or fault conditions, the DC grid is disconnected from the AC grid, and it is then switched to stand-alone operation, in which the generated and stored power are supplied to the loads connected to the DC grid, hence, loads can be operated continuously without instantaneous interruption; (3) the cost and losses involved with the DC system can be reduced because only a single $\mathrm{AC}$ grid connected inverter unit is needed; (4) distributed generators usually supply DC power. Therefore, the phase detection associated with the AC grid is not needed. Thus, the cost and loss of the system can be reduced; and (5) although a DC distribution line is required, the cost performance of DC houses, hospitals, and information centers are satisfactory [4].

At present, only AC smart grids are used in practical applications, whereby the DCSG (DC smart grid) has been proposed by the authors [5-8]. In Refs. [5, 6], the authors have proposed the operation of a DC MSG (DC micro smart grid) and the multi DC smart grid in isolated mode. However, there was no discussion on how the DC MSG will operate in insolation mode, especially if there is less power generation in comparison to load demand. Moreover, the operation in deficit or surplus power in the system was not considered.

In Refs. [7, 8], the authors covered the earlier mentioned cases and proposed protection of the DC transmission line in multi DC smart grid operation, respectively. Nevertheless, neither of the papers considered controllable load and power flow management during the grid connected mode of operation.
In this paper, the fuzzy logic control has been used for controlling PWM (pulse width modulation) delay angle of the DABSRCs (dual active bridge series resonant converters) for different operation conditions. These includes: controllable load's SOC (state of charge) management, DC feeder's voltage stability and power flow management between the grid side and the DCSG. The fuzzy logic control is used due to its benefits compare to other controls which includes: design simplicity, robustness and minimal requirement for accurate mathematical model [9], can be well implemented to low-resolution analogue to digital converters and low-cost systems based on cheap sensors [10].

The proposed DCSG consists of a PMSG (permanent magnet synchronous generator) WT (wind turbine) and PV generation, a WT generator inverter, a PV boost converter, a GS (grid-side) and CL (controllable load) DABSRCs, controllable loads, and normal DC loads. During the DCSG operation, the DC distribution line voltage fluctuations due to power supplied by the renewable energy plants (WT and PV) and loads are suppressed by applying the power consumption control to the CL. In the case where the CL cannot stabilize the system, the GS converter will participate in power stabilization and CL management by power transfer operation between DCSG and grid.

This paper has been organized as follows: Section 2 describes the modeling of all components of the power system including WT and PV generators, converters and loads with their control system. Section 3 discusses the results, which are obtained in different operation cases. The paper is finalized with Section 4 which will present conclusions from this work.

\section{Power System Modeling and Control}

The proposed DCSG power system as shown in Fig. 1 contains a WT and PV generators, variable DC loads, controllable loads, a generator-side converter, $C_{W T}$, $\mathrm{PV}$ boost converter, $C_{P V}$, and bidirectional DC/DC converters, DABSRCs, for connecting the controllable 


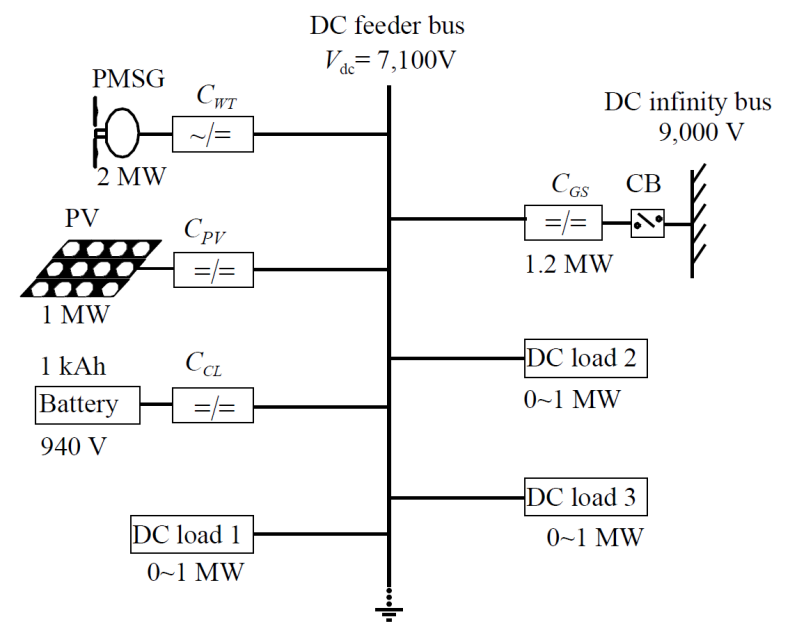

Fig. 1 The system configuration block diagram of the DC smart grid.

loads, $C_{B}$, as well as the grid, $C_{G S}$, which is connected to DC infinity bus though DC CB (circuit breaker). The PMSG's and PV's output power are supplied to the DC loads through the DC feeder (DC distribution line). When excess power in PMSG and PVs is generated relative to the loads demand, it is supplied to the grid through the grid connected converter. The grid connected and controllable load DABSRCs control their output power to maintain: (1) feeder's voltage, $V_{d c}$ within a range of $\pm 5 \%$, and (2) operation management of controllable load power's SOC within the acceptable range of $80 \%-20 \%$ for upper and lower limits [11]. The operations of the converters are controlled using fuzzy logic control.

\subsection{Wind Energy Conversion System}

The WTG (wind turbine generator) is a gearless $2 \mathrm{MW}$ PMSG as modeled in Refs. [12-14]. The PMSG has a simple structure and high efficiency; it is expected to be installed in the next generation of WTG systems. Wind power energy obtained from the windmill is sent to the PMSG. In order to generate maximum power, the rotational speed of the PMSG is controlled by the PWM converter. The generator-side converter controls the rotational speed of the PMSG in order to achieve variable speed operation with MPPT (maximum power point tracking) control and implements the maximum torque control [15, 16]. Optimum rotational speed of the PMSG used in this paper is approximated as in Eq. (1) for MPPT [5]:

$$
\omega_{e_{-} \text {opt }}=2.0615 V_{w}
$$

where, $\omega_{\text {e_opt }}$ is optimum rotational speed of the PMSG in $\mathrm{rad} / \mathrm{s}$ and $V_{w}$ is wind speed in $\mathrm{m} / \mathrm{s}$.

Generally, the MPPT control is applied when $V_{w}$ is smaller than the rated wind speed, $V_{r w}$. If the $V_{w}$ is greater than $V_{r w}$, then the output power of the PMSG is controlled by the pitch angle $(\beta)$ control system. When $V_{w}$ ranges between cut-in $V_{w}(5 \mathrm{~m} / \mathrm{s})$ to rated $V_{w}(12$ $\mathrm{m} / \mathrm{s}$ ), the $\beta$ is set to $0^{\circ}$, since wind windmill energy is maximum at $0^{\circ}$ [14], when $V_{w}$ is between $V_{r w}$ and the cut-out $V_{w}(24 \mathrm{~m} / \mathrm{s})$, the pitch angle is controlled to deliver windmill output $\left(P_{g}=1\right)$, when the $V_{w}$ is above the cut-out $V_{w}$ the $\beta$ is set to $90^{\circ}$ because the energy of a windmill is the smallest at $90^{\circ}$. The control diagram is shown in Fig. 2. The detailed pitch angle control was described in Ref. [17].

The speed control of the PMSG is realized on a rotating frame, where the rotational speed error from optimum rotational speed, $\omega_{\text {e_opt }}$ and measured rotational speed, $\omega_{e}$ are used as the input of the speed controller $\left(P I_{1}\right)$, which produces, $q$ axis stator current command, $i_{1 q}{ }^{*}$ as shown in Fig. 3. Generally, the salient pole type synchronous machine is desirable to control the $d$-axis stator current, $i_{1 d}$ and the reference $i_{1 d}{ }^{*}$ as expressed in Eq. (2).

$$
i_{1 d}^{*}=\frac{\phi_{f}}{2\left(L_{d}-L_{q}\right)}-\sqrt{\frac{\phi_{f}^{2}}{4\left(L_{q}-L_{d}\right)^{2}}+i_{1 q}^{2}}
$$

where, $\phi_{f}$ is the permanent magnetic flux, $L_{d}$ and $L_{q}$ are the $d q$-axis inductance, and $i_{1 q}$ is the $q$-axis current. The parameters of the PMSG and windmill are shown in Table 1 [5].

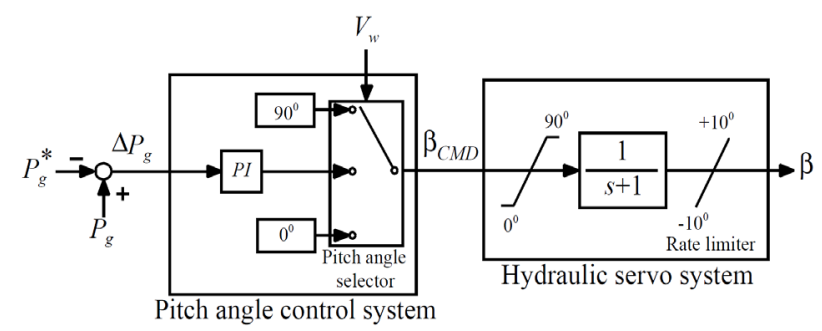

Fig. 2 Pitch angle control system. 


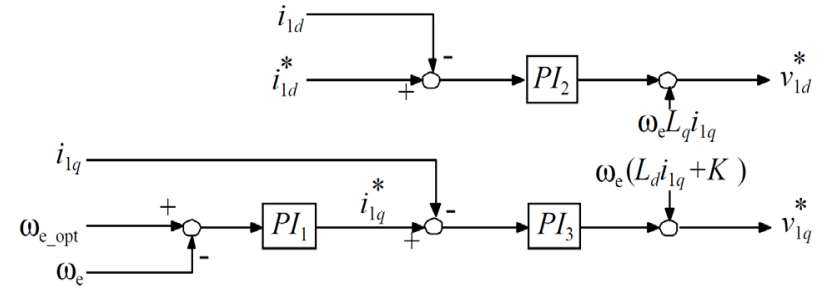

Fig. 3 Generator-side converter control system.

\subsection{PV System}

PV generation is very important for the utilization of renewable energy provided by the sun. A PV generator converts solar or artificial light to electric energy due to the movement of positive and negative charge carriers when the light strikes its surface. Normally, the PV generation systems suffer low energy conversion efficiency due to non-linear variations of output voltage and current, which is caused by environmental and operational conditions [18]. These include: ambient temperature, operating temperature, insulation, dirt, sunlight characteristics and load current technologies [18, 19]. Different methods have been used and proposed for solving this problem, such as: (1) sun tracking; (2) MPPT; and (3) a combination of both [19].

Single diode PV model as in Refs. [20, 21] has been used for modeling the PV generation system in this research. Eq. (3) describes the output current $(I)$ of the PV from the model.

$$
I=I_{L}-I_{D}
$$

where,

$$
\begin{gathered}
I_{D}=I_{0}\left(e^{\frac{q\left(V+I R_{S}\right)}{n k T}}-1\right) \\
I_{L}=I_{L}\left(T_{1}\right)\left(1+K_{0}\left(T-T_{1}\right)\right) \\
I_{L\left(T_{1}\right)}=\frac{G I_{S C\left(T_{1, n o m}\right)}}{G_{(\text {nom })}} \\
K_{0}=\frac{I_{S C\left(T_{2}\right)}-I_{S C\left(T_{1}\right)}}{T_{2}-T_{1}}
\end{gathered}
$$

where, $I_{L}$ is the current source which is equal to the short circuit current, $I_{S C}$ and directly proportional to solar irradiance, $G\left(\mathrm{~W} \cdot \mathrm{m}^{2}\right), R_{s}$ is the series resistance, $I_{0}$ is the reverse saturation current of the diode, $q$ is the electron charge $\left(1.60 \times 10^{-19} \mathrm{C}\right), V_{d}$ is the voltage across
Table 1 Parameters of wind turbine generator.

\begin{tabular}{llll}
\hline Rated power & $P_{\text {ref }}$ & 2 & $\mathrm{MW}$ \\
Rated wind speed & $V_{w_{-} r e f}$ & 12 & $\mathrm{~m} / \mathrm{s}$ \\
Stator resistance & $R_{a}$ & 0.01 & $\mathrm{pu}$ \\
Leakage inductance & $L_{\mathrm{ls}}$ & 0.1 & $\mathrm{pu}$ \\
Stator $d / q$ axis inductance & $L_{d}, L_{q}$ & $1 / 0.65$ & $\mathrm{pu}$ \\
Number of pole pairs & $p$ & 11 & \\
Field flux & $K$ & 136.25 & $\mathrm{~Wb}$ \\
Radius of wind turbine rotor & $R$ & 38 & $\mathrm{~m}$ \\
Equivalent inertia & $J_{e q}$ & 8,000 & $\mathrm{~kg} \cdot \mathrm{m}^{2}$ \\
Rotational damping & $D$ & 0 & \\
\hline
\end{tabular}

the diode, $k$ is Boltzmann constant $\left(1.38 \times 10^{-23} \mathrm{~J} / \mathrm{K}\right), T$ is the junction temperature $(\mathrm{K}), T_{1}$ is the standard $\mathrm{PV}$ designed temperature $\left(25{ }^{\circ} \mathrm{C}\right), T_{2}$ is the ambient temperature $\left({ }^{\circ} \mathrm{C}\right)$ and $n$ is the diode ideality factor.

In this paper, in order to generate maximum and optimum power from the PV system as the temperature, insolation and load varies, a maximum power point tracker has been implemented to DC/DC boost converter connected between the PV system and distribution line as shown in Fig. 4. The PV modules have been modeled and arranged in parallel and series to give out power of $1 \mathrm{MW}$. The PV module has been modeled as of BP365 $65 \mathrm{~W}$ with the specifications shown in Table 2.

DC distribution bus $7,100 \mathrm{~V}$

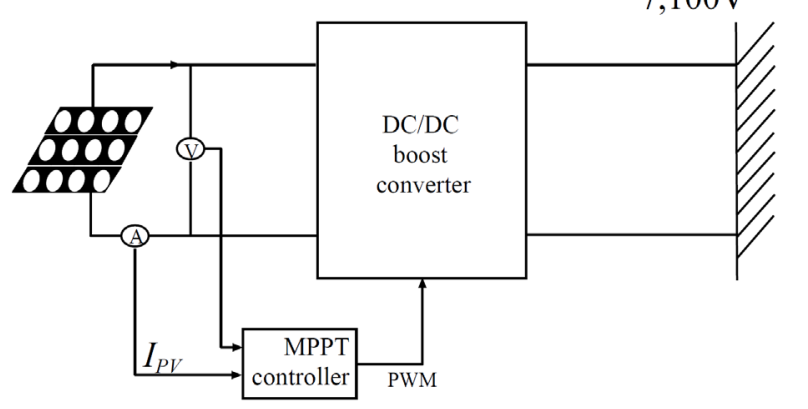

Fig. 4 PV system model.

Table 2 Specifications of the BP365 $65 \mathrm{~W}$ PV module.

\begin{tabular}{llll}
\hline Maximum power & $P_{\mathrm{m}}$ & 65 & $\mathrm{~W}$ \\
Voltage, max power & $V_{m}$ & 17.6 & $\mathrm{~V}$ \\
Current, max power & $I_{m}$ & 3.69 & $\mathrm{~A}$ \\
Open circuit voltage & $V_{O C}$ & 22.1 & $\mathrm{~V}$ \\
Short circuit current & $I_{S c}$ & 3.99 & $\mathrm{~A}$ \\
\hline
\end{tabular}




\subsection{Controllable Loads}

In this paper, the DC feeder voltage is maintained by the voltage control of the DC/DC converter connected to the controllable loads. Batteries are used as controllable loads. Although the battery is installed in DC houses, the EV (electric vehicle) will be also used as a battery in the future. The EV is important due to the depletion of energy sources and its availability as a backup power in the residential houses.

The battery is modeled as from Refs. [22, 23]. Terminal voltage, $E_{b}$ and state of charge, SOC are calculated by Eqs. (4) and (5), respectively. A 940 V/1 kAh battery was modeled and used in the power system. In order to show all simulation condition results with high and low battery capacity, the charging and discharging time constant of $14 \mathrm{~s}$ was used instead of actual time of $1 \mathrm{~h}(3,600 \mathrm{~s})$.

$$
\begin{gathered}
E_{b}=E_{0}-R_{b} i_{b}-K \frac{Q}{Q+\int i_{b} \mathrm{~d} t}+A e^{\left(-B i_{b} \mathrm{~d} t\right)} \\
S O C=100\left(1-\frac{\int i_{b} \mathrm{~d} t}{Q}\right)
\end{gathered}
$$

where, $E_{0}$ is the battery constant voltage $(\mathrm{V}), R_{b}$ is internal resistance of the battery $(\Omega), i_{b}$ is the battery charging current (A), $Q$ is the battery capacity (Ah), $K$ is the polarization voltage $(\mathrm{V}), A$ is exponential voltage (V) and $B$ is the exponential capacity (1/Ah).

\subsection{Bidirectional Converter}

The bidirectional converters chosen in this study to connect the controllable loads and grid bus to the DC distribution line are DABSRC as shown in Fig. 5. DABSRC has been chosen due to its numerous advantages such as, small size, low cost, simple control and high power density [24, 25]. Ref. [26] mentioned different modulation methods for these converters. In this paper, phase shift modulation was used. Among the advantages of this method are low complexity of computations for the phase shift method, simplicity of the circuit, and a reduction of power loss due to ZVS (zero voltage switching) [27].
The detailed AC analysis of this converter was described in Refs. $[24,25]$. The output active power, $P_{0}$ which is the average value of instantaneous power, tank parameters, inductor, $L_{s}$ and capacitor, $C_{s}$ are given by Eqs. (6)-(8), respectively.

$$
\begin{gathered}
P_{0, p u}=\frac{1}{2 \pi} \int_{0}^{2 \pi} P_{p u}(t) \mathrm{d}\left(\omega_{s} t\right)=\frac{8 M}{\pi^{2} Q\left(F-\frac{1}{F}\right)} \sin \varphi \\
Q=\frac{\omega_{r} L_{s}}{R_{L}^{\prime}} \\
F=\frac{\omega_{s}}{\omega_{r}}=\frac{f_{s}}{2 \pi \sqrt{L_{s} C_{s}}}
\end{gathered}
$$

where,

$$
M=V_{0}^{\prime} / V_{i}=n_{t} \frac{E_{2}}{E_{1}}
$$

$R_{L}^{\prime}$ is the load resistance transferred to the primary side, $\omega_{r}$ is angular resonant frequency, $f_{s}$ is switching frequency, $n_{t}: 1$ is transformer turns ratio, $V_{0}^{\prime}$ is output voltage transferred to the primary side, $V_{i}$ is primary input voltage and $\varphi$ is phase shift angle.

Eq. (6) can be used to determine $\varphi$ for the amount of power delivered to either side of the converter, whereas the net power flow is positive with $\varphi>0$ and negative with $\varphi<0$. In Refs. [24, 25], the design curves were used to obtain the optimized values of voltage gain, $(M$ $=0.95)$, normalized frequency, $(F=1.1)$, and value of $Q$ which is equal to 1 for achieving soft switching, lower resonant current, high efficiency and small tank size. Table 3 shows the design parameters for controllable load and grid side bidirectional converters.

\subsubsection{Fuzzy Logic Control Strategy for DABSRCs}

Fuzzy logic is used in this paper for controlling the phase shift angle of the PWM of bidirectional converters. In controllable load's DABSRC, the fuzzy

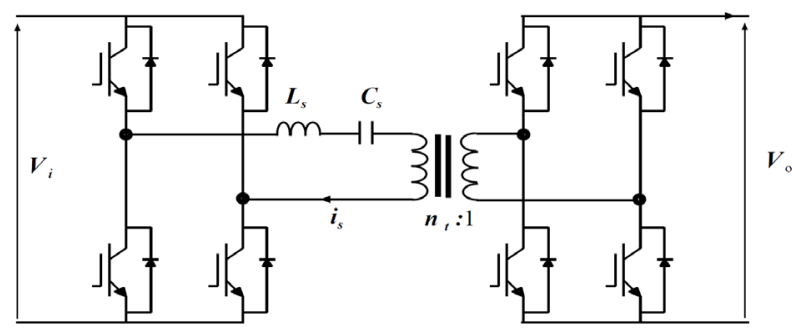

Fig. 5 Dual active bridge series resonant converter. 
logic control strategy used for controlling phase shifting angle of PWM resulted from $V_{d c}$ voltage fluctuations. This control has three inputs, error in $V_{d c}, e$, $\Delta e$ and $\Delta^{2} e$ as shown in Fig. 6, where their membership functions and fuzzy rules are shown in Fig. 7 and Table 4 , respectively.

Cascaded fuzzy logic controller was used in the grid side converter as presented in Fig. 8. The first part determines the amount of power, $\Delta P$ to be delivered to either side due to the SOC, power flow from the battery (i.e., battery current), and $V_{d c}$. Their membership functions and fuzzy rule are as shown in Fig. 9 and Table 5, respectively. The second part is the same in operation as that of controllable load converter (fuzzy 1 controller) but with different input limits of $e, \Delta e$ and $\Delta^{2} e$.

\subsubsection{Controllable Load DABSRC Control}

In this paper, the $\mathrm{DC}$ distribution voltage is controlled by both DABSRC converters connected to the controllable load and the infinite supply (grid). During power system operation, the main targets are to minimize the energy flow from the infinite supply to the DCSG, to maximize the power delivered to the infinite supply, yet maintain a stable DC distribution voltage and SOC management. The proposed control system for the DABSRC connected to the controllable load has the role of ensuring a stable DC distribution voltage, as illustrated in Fig. 7. In this control system, the DC feeder voltage fluctuations in the DCSG due to RES and load variation is suppressed by the phase shift angle command of the DABSRC connected to the controllable load. The phase shift angle for the amount of delivered power is determined by the fuzzy controller based on the amount of voltage fluctuation. The error between the $V_{d c}{ }^{*}$ and $V_{d c}$ is used to determine the angle for active power flow in the DABSRC. If $V_{d c}$ is less than the $V_{d c}{ }^{*}$, the fuzzy controller will determine and give positive PWM phase shift angle for power flow from the controllable load to the distribution line. If $V_{d c}$ is greater than $V_{d c}{ }^{*}$, negative PWM phase shift angle will be given by the controller for power flow from the distribution line to the controllable load.

Table 3 DABSRCs design parameters.

\begin{tabular}{llll}
\hline Parameter & Abbreviation & $\begin{array}{l}\text { Cload } \\
\text { DABSRC }\end{array}$ & GS DABSRC \\
\hline $\begin{array}{l}\text { Rated active } \\
\text { power }(\mathrm{MW})\end{array}$ & $P_{0}$ & 1.00 & 1.20 \\
Voltage $(\mathrm{V})$ & $E_{1} / E_{2}$ & $7,100 / 940$ & $7,100 / 9,000$ \\
Turns ratio & $n: 1$ & 7.18 & 0.75 \\
Switching & $f_{s}$ & 100 & 100 \\
Frequency $(\mathrm{kHz})$ & $C_{s}$ & 38.48 & 46.18 \\
Capacitor $(\mu \mathrm{F})$ & $L_{s}$ & 79.65 & 66.37 \\
Inductor $(\mathrm{mH})$ & $L_{s}$ & &
\end{tabular}

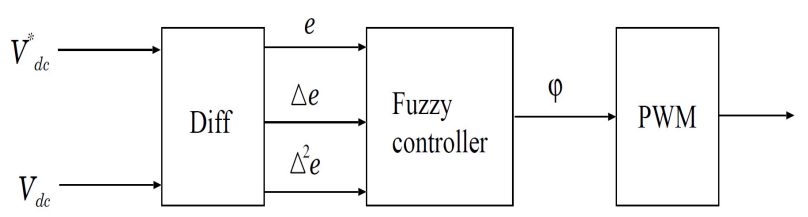

Fig. 6 Controllable load control system.
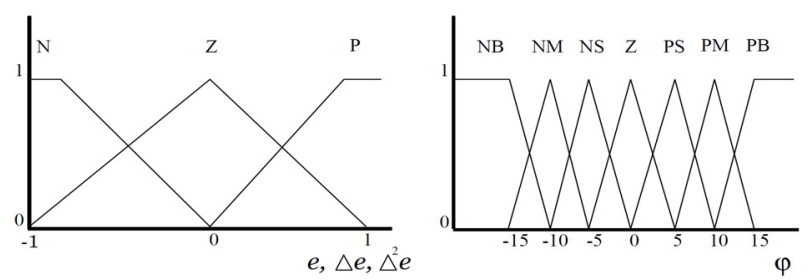

Fig. 7 Fuzzy 1 membership functions.

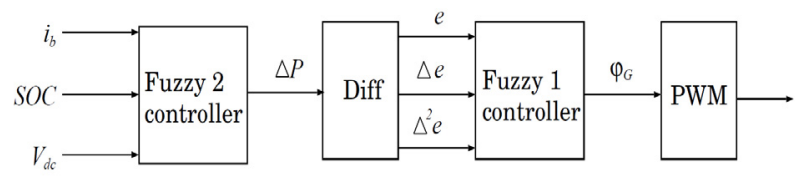

Fig. 8 Grid side converter control system.

Table 4 Fuzzy 1 rules for $\varphi$.

\begin{tabular}{|c|c|c|c|c|c|c|c|c|c|c|}
\hline \multirow[b]{3}{*}{$\Delta e$} & & \multicolumn{9}{|c|}{$e$} \\
\hline & & \multicolumn{3}{|c|}{$\mathrm{N}$} & \multicolumn{3}{|c|}{$\mathrm{Z}$} & \multicolumn{3}{|c|}{$\mathrm{P}$} \\
\hline & & $\mathrm{N}$ & $Z$ & $\mathrm{P}$ & $\mathrm{N}$ & $\mathrm{Z}$ & $\mathrm{P}$ & $\mathrm{N}$ & $Z$ & $\mathrm{P}$ \\
\hline \multirow{3}{*}{$\Delta^{2} e$} & $\mathrm{~N}$ & NB & NB & NM & NM & NS & $\mathrm{Z}$ & $Z$ & PS & $\mathrm{PM}$ \\
\hline & $\mathrm{Z}$ & NB & $\mathrm{NM}$ & NS & NS & $\mathrm{Z}$ & PS & PS & $\mathrm{PM}$ & PB \\
\hline & $\mathrm{P}$ & NM & NS & Z & Z & PS & PM & PM & PB & PB \\
\hline
\end{tabular}

$\mathrm{N}=$ negative, $\mathrm{NB}=$ negative big, $\mathrm{NM}=$ negative medium, $\mathrm{Z}=$ zero, $\mathrm{P}=$ positive, $\mathrm{PM}=$ positive medium, $\mathrm{PB}=$ positive big. 

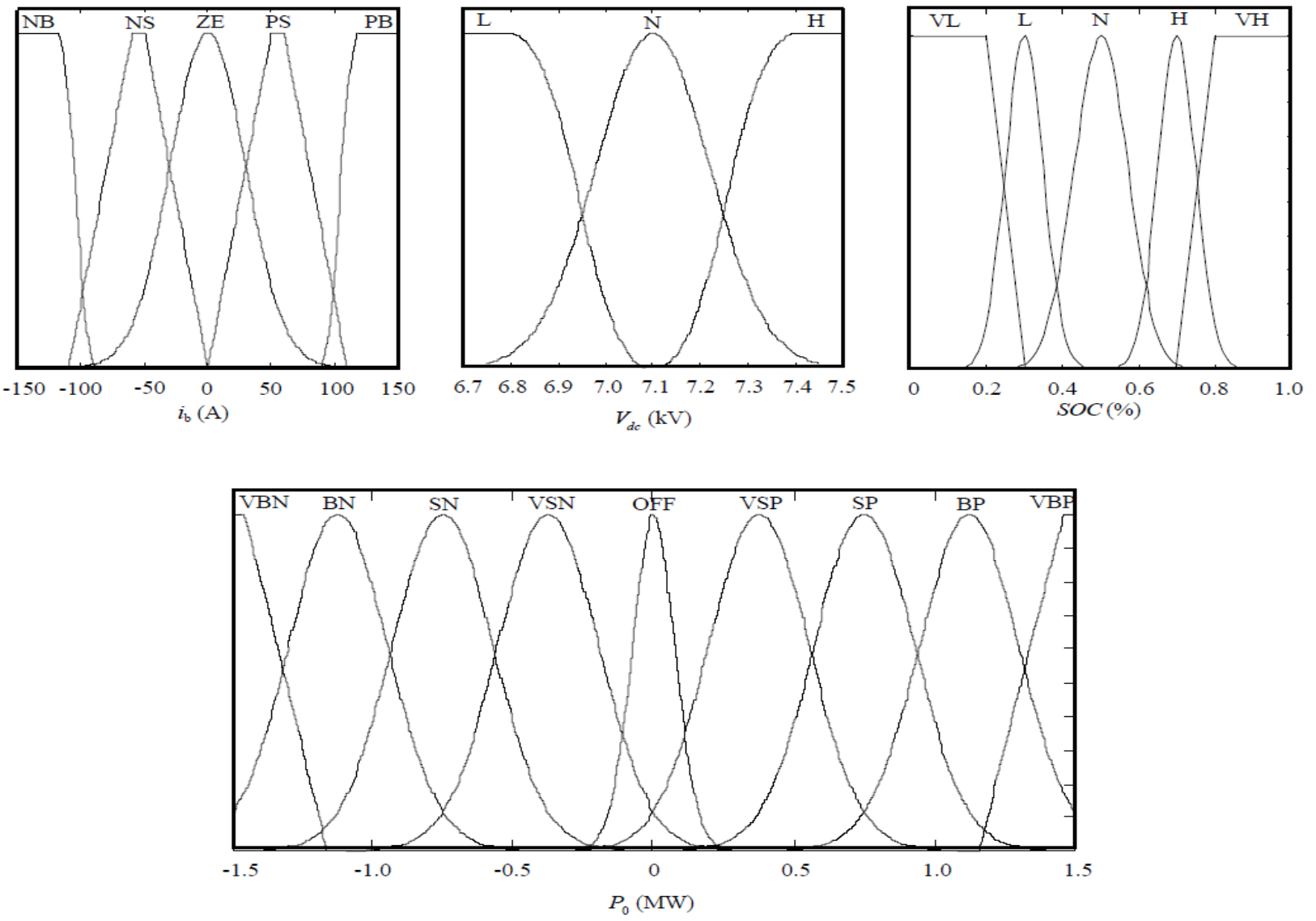

Fig. 9 Fuzzy 2 membership functions.

Table 5 Fuzzy 2 rules for $\Delta P_{0}$.

\begin{tabular}{|c|c|c|c|c|c|c|c|c|}
\hline \multirow[b]{3}{*}{$i_{b}$} & & \multicolumn{7}{|c|}{$V_{d c}$} \\
\hline & & \multicolumn{3}{|l|}{$\mathrm{H}$} & \multicolumn{2}{|c|}{$\mathrm{N}$} & \multirow[b]{2}{*}{ BP } & \multirow{2}{*}{$\mathrm{L}$} \\
\hline & & $\mathrm{BN}$ & $\mathrm{BN}$ & SN & Z & SP & & \\
\hline \multirow{5}{*}{$S O C$} & VL & VSN & VSP & SP & BP & VBP & VBP & VBP \\
\hline & $\mathrm{L}$ & SN & Z & Z & Z & $\mathrm{Z}$ & $\mathrm{Z}$ & LP \\
\hline & $\mathrm{N}$ & SN & Z & Z & Z & $\mathrm{Z}$ & Z & SP \\
\hline & $\mathrm{H}$ & BN & Z & Z & Z & $\mathrm{Z}$ & Z & SP \\
\hline & $\mathrm{VH}$ & VBN & VBN & VBN & $\mathrm{BN}$ & SN & VSN & VSP \\
\hline
\end{tabular}

$\mathrm{VBN}=$ very big negative, $\mathrm{BN}=$ big negative, $\mathrm{SN}=$ small negative, $\mathrm{Z}=$ zero, $\mathrm{SP}=$ small positive, $\mathrm{BP}=$ big positive, $\mathrm{VBP}=$ very big positive, $\mathrm{VL}=$ very low, $\mathrm{L}=$ low, $\mathrm{N}=$ normal, $\mathrm{H}=$ high, $\mathrm{VH}=$ very high.

\subsubsection{Grid Side DABSRC Control}

With a surfeit or deficit of power generation over the load demand, or when the SOC management of the controllable load is needed, the grid connected DABSRC is controlled to stabilize the power system. By power transfer operation between the DCSG and the grid, distribution line voltage stabilization and SOC management are guaranteed. In the case of power transfer, when excess power is generated or a deficiency of power occurs in a DCSG, the amount of the power to be transferred to either side is determined by the fuzzy controller shown in Fig. 8. The first part determines the amount of power, $\Delta P$ to be delivered to either side and thesecond part is fixing PWM shift angle corresponding to the calculated $\Delta P$. Therefore, $V_{d c}$ of the DCSG is also controlled according to the energy transfer between DCSG and grid side when the grid side converter is in operation. 


\section{Simulation Results}

The simulation of the power system model in Fig. 1 has been carried out for different operation cases of the DCSG. Figs. 10 and 11 present the wind speed and solar insolation for WT and PV power generation. The generated active power from WT $\left(P_{W T}\right), \mathrm{PV}\left(P_{P V}\right)$ and their summation $\left(P_{T G}\right)$ are presented in Figs. 12-14, respectively.

Furthermore, Fig. 15 shows three DC loads $\left(P_{L}\right)$ with a maximum consumption of $1 \mathrm{MW}$ each switched in different capacities to show the effectiveness of the power system, while Fig. 16 describes the total combined DC load $\left(P_{T L}\right)$ as seen by the control system during operation. For power stabilization in the DCSG, due to power generation and load variation during simulation, the controllable load converter phase shift angle $\left(\varphi_{\mathrm{CL}}\right)$ is shown in Fig. 17 and its corresponding active power output $\left(P_{C L}\right)$ is shown in Fig. 18. Whereas, a phase shift angle of grid converter $\left(\varphi_{G}\right)$ is shown in Fig. 19 with its active output power $\left(P_{G}\right)$ in Fig. 20.

Moreover, despite the power generation and load variations, Fig. 21 shows that, the SOC of the battery is well maintained within acceptable operating boundaries and also the distribution line voltage, $V_{d c}$ always stays within acceptable limits of $\pm 5 \%$ of $V_{d c}$ as shown in Fig. 22.

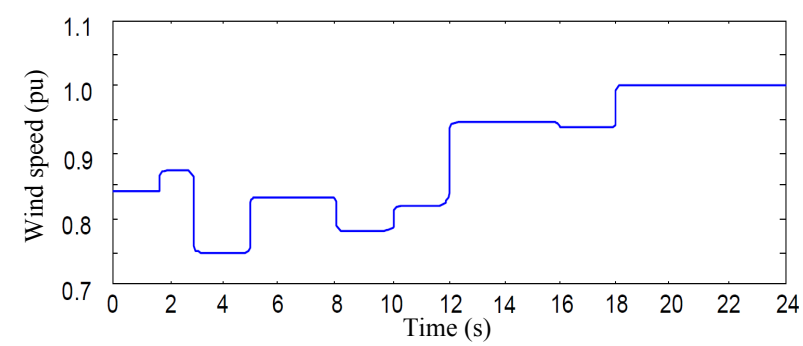

Fig. 10 Wind turbine speed.

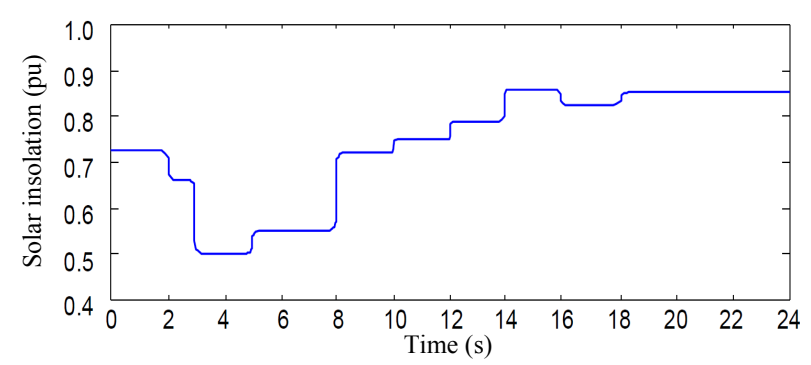

Fig. 11 Solar insolation.

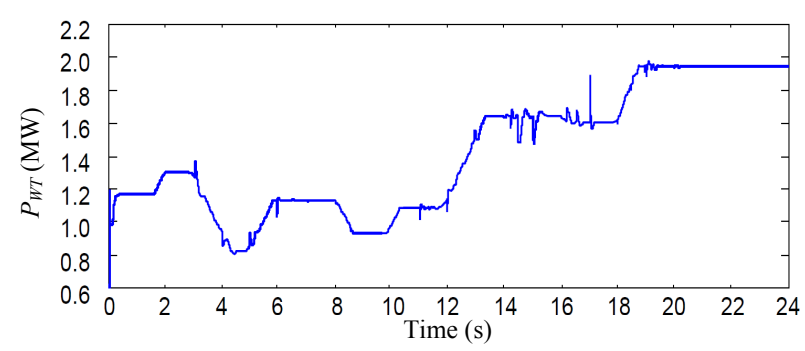

Fig. 12 Wind turbine active power.

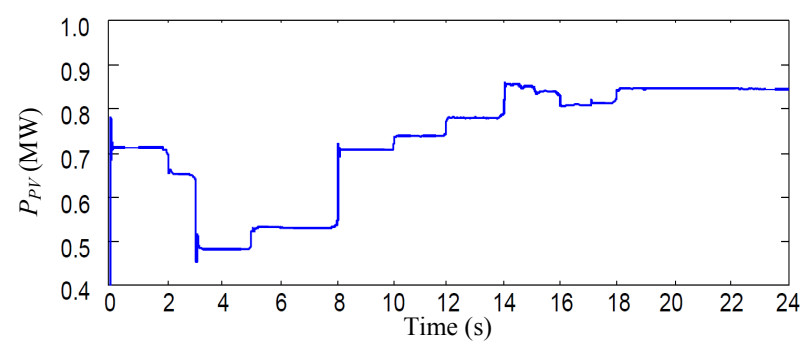

Fig. 13 Photovoltaic active power.

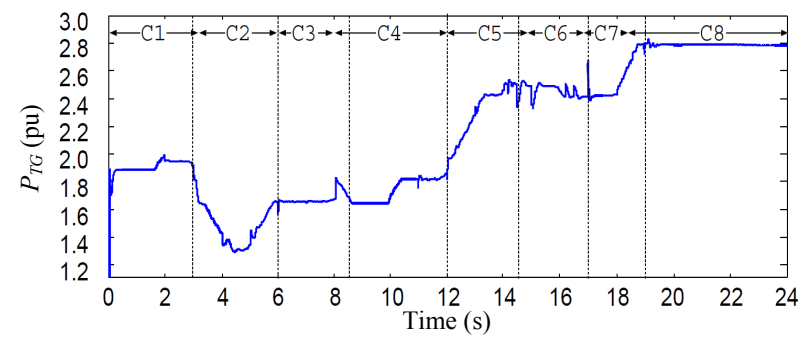

Fig. 14 Total active power generation.

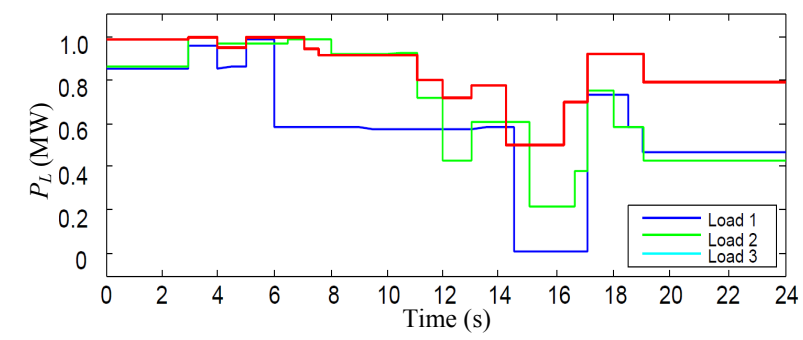

Fig. 15 DC loads .

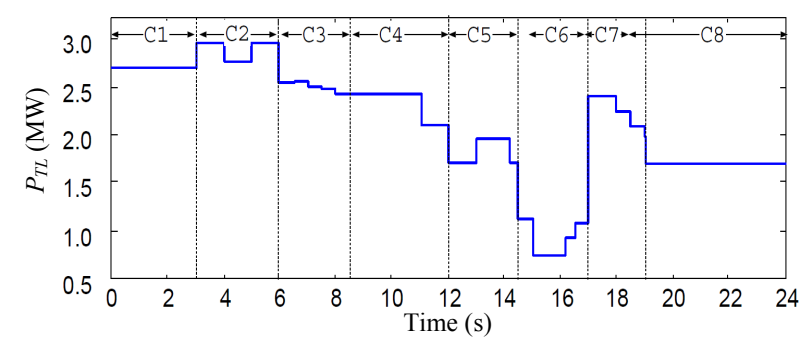

Fig. 16 Total DC loads.

Apart from that, in the simulation results shown from Figs. 10-22, different scenarios have been tested during the simulation to show how the power system will react in response to changes in power generation, load variation and the on-line battery SOC. These 
scenarios are explained from Case 1 to Case 8 (C1-C8), and their summaries are presented in Table 4.

Case 1: This case presents the operation mode of DCSG in which the power generated from WT and PV, and load demand are balanced as shown in the simulation results from $t=0 \mathrm{~s}$ to $t=3 \mathrm{~s}$. Different DC load capacities have been switched in order to show the demand response operation of the system. Since the SOC of the controllable load (battery) is high and the load power demand can be fulfilled by the controllable load alone, hence the output power of the grid converter is kept at zero as shown in Fig. 20 and $V_{d c}$ is kept constant at the nominal value of $7,100 \mathrm{~V}$ as shown in Fig. 22. Therefore, the $V_{d c}$ voltage is kept within the acceptable range in isolated mode.

Case 2: This scenario is shown in the simulation results from $t=3 \mathrm{~s}$ to $t=6 \mathrm{~s}$. In this case, even though the SOC is within the desired operating region as shown in Fig. 21, the $V_{d c}$ in Fig. 22 starts to drop due to insufficient power from controllable loads, which are operating at maximum output power as shown in Fig. 18, and low power generation from the RES, as shown in Fig. 14. Hence, the grid converter gives power to the DCSG as shown in Fig. 20 so that the $V_{d c}$ is maintained at the accepted range.

Case 3: From $t=6 \mathrm{~s}$ to $t=8.5 \mathrm{~s}$, power generation increases as shown in Fig. 14. Since the SOC is within the desired operating region as shown in Fig. 21, and the batteries can be used to stabilize $V_{d c}$ and maintain it constant at the nominal value of $7,100 \mathrm{~V}$ as shown in Fig. 22, therefore, the grid converter power output to the DCSG was abstained.

Case 4: From $t=8.5 \mathrm{~s}$ to $t=12 \mathrm{~s}$ though the battery can still supply power to stabilize the $V_{d c}$ at $7,100 \mathrm{~V}$, at $t=8.5 \mathrm{~s}$ the lower limit of the SOC was approached as shown in Fig. 21. The grid converter was controlled to give power to the DCSG so that SOC can be improved.

Case 5: In this case, the SOC has been improved enough for the battery alone to control the $V_{d c}$ fluctuations as shown in Fig. 21 from $t=12 \mathrm{~s}$ to $t=$ $14.5 \mathrm{~s}$. Since the $V_{d c}$ is kept at $7,100 \mathrm{~V}$ by the controllable load converter as shown in Fig. 22, therefore, the grid converter gives no power to the DCSG as shown in Fig. 20.

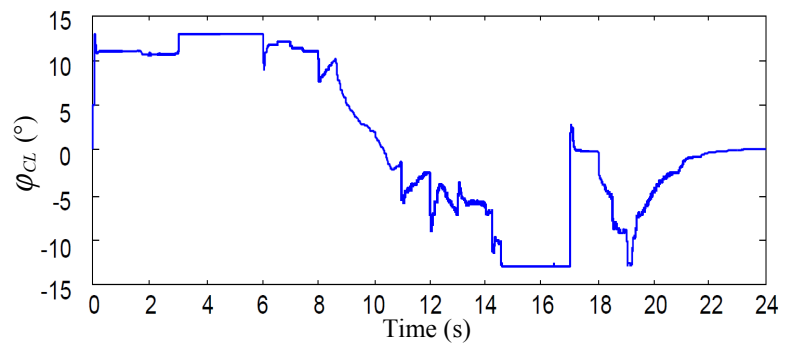

Fig. 17 Phase shift angle of controllable load converter.

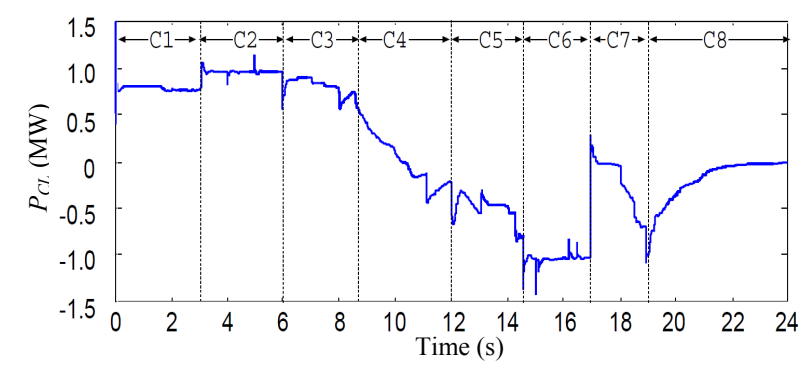

Fig. 18 Controllable load active power.

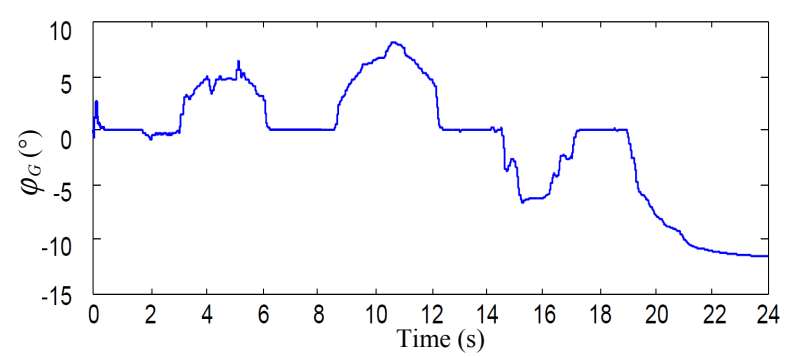

Fig. 19 Phase shift angle of grid converter $\left(\varphi_{G}: \varphi\right.$ of grid side converter).

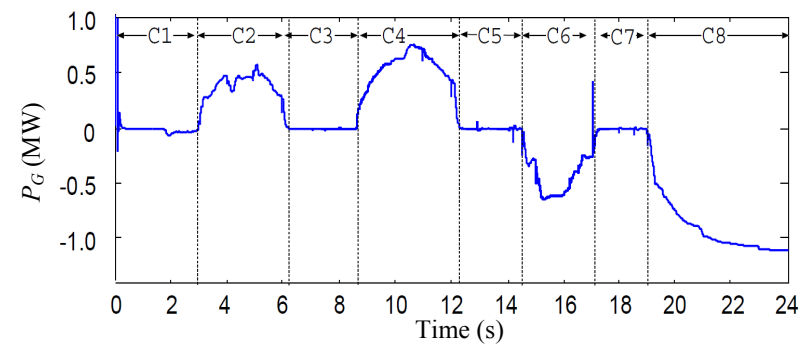

Fig. 20 Grid converter active power.

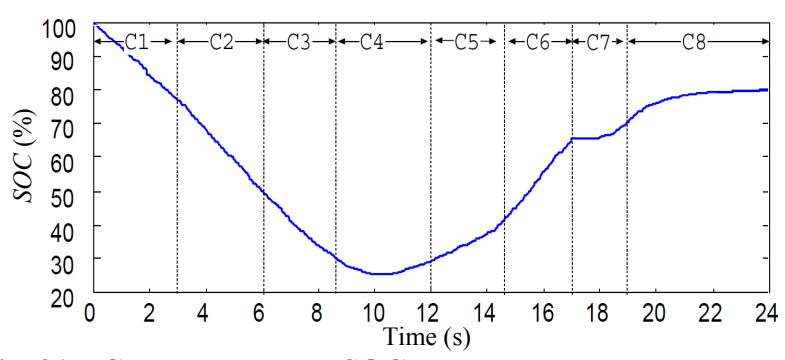

Fig. 21 Controllable load SOC. 
Table 6 Simulation results summary.

\begin{tabular}{lllllll}
\hline Cases & Time interval (s) & SOC & Load demand & CL converter & GS converter & $V_{d c}$ \\
\hline 1 & $0-3$ & High & Balanced & Control $V_{d c}$ & No power output & Constant at 7,100 V \\
2 & $3-6$ & Within the range & High & Give maximum power & Give power & Within the range \\
3 & $6.5-8.5$ & Within the range & Balanced & Control $V_{d c}$ & No power output & Constant at 7,100 V \\
4 & $8.5-12$ & Low & Balanced & Control $V_{d c}$ & Give power & Constant at 7,100 V \\
5 & $12-14.5$ & Within the range & Balanced & Control $V_{d c}$ & No power output & Constant at 7,100 V \\
6 & $14.5-17$ & Within the range & Low & Take maximum power & Take power & Within the range \\
7 & $17-19$ & Within the range & Balanced & Control $V_{d c}$ & No power output & Constant at 7,100 V \\
8 & $19-24$ & High & Low & No power output & Take power & Constant at 7,100 V \\
\hline
\end{tabular}

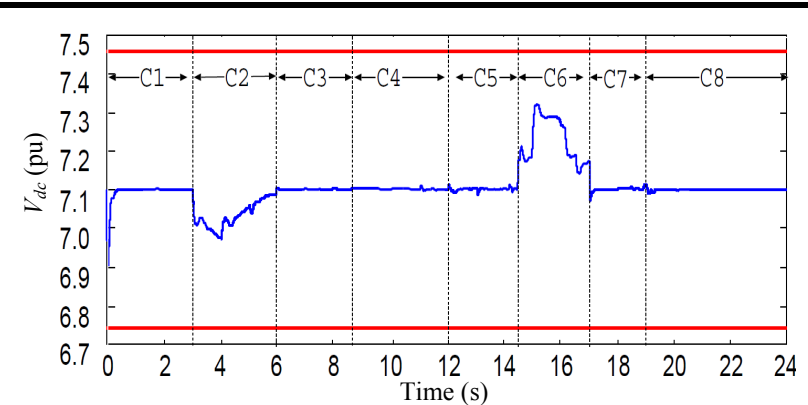

Fig. 22 Distribution line voltage.

Case 6: From $t=14.5 \mathrm{~s}$ to $t=17 \mathrm{~s}$, the DC load decreased significantly and caused extra power generated exceeding load demand in the DCSG. Even though the battery SOC is within the desired operating region as shown in Fig. 21, but since it was charging to its full capacity as shown in Fig. 18 and still the extra power tend to increase the $V_{d c}$, the grid converter was controlled to supply power to the grid in order to keep the $V_{d c}$ at its allowable range as shown in Fig. 22.

Case 7: From $t=17 \mathrm{~s}$ to $t=19 \mathrm{~s}$, the DC loads increased as shown in Fig. 16. Since the battery's SOC is in the desired operation region as shown in Fig. 21 and the $V_{d c}$ voltage was kept at the nominal value of $7,100 \mathrm{~V}$ as shown in Fig. 22, the grid side converter power flow became zero as shown in Fig. 20.

Case 8: The last scenario was presented from $t=19 \mathrm{~s}$ to $t=24 \mathrm{~s}$. The power generated from WT and PV was increased as shown in Fig. 14. It is shown in Fig. 21 that, the SOC approached the maximum charge limit while connected to the grid at $t=19 \mathrm{~s}$. Therefore, the grid side converter controlled to the take extra power exceeding the load demand to prevent the battery from over charging. Hence the SOC was maintained at its safe upper limit as shown in Fig. 21.

\section{Conclusions}

In this paper, the application of FLC on DABSRC for the DCSG power system was proposed. In order to show the effectiveness of the power system, different simulation scenarios were analyzed and simulation results were presented. It has been shown that, the power system can work under different conditions as analyzed in the aforementioned cases. In its operation, the DCSG transferred power to and from the infinite grid for surplus and deficit, and stabilized the power in regards to RES power generation and load fluctuations. In this work, there was no specific case presenting the isolated mode of operation of the DCSG, but with the scenarios in which the results were presented, it can be determined that, the power system can withstand insolation mode as it resembles those scenarios in which the grid converter power flow was zero (Case 1, Case 3, Case 5 and Case 7).

\section{References}

[1] Aizebeokhai, A. P. 2009. "Global Warming and Climate Change: Realities, Uncertainties and Measures." International Journal of Physical Sciences 4 (13): 868-79.

[2] Samad, T., and Kiliccote, S. 2012. "Smart Grid Technologies and Applications for the Industrial Sector." Computers and Chemical Engineering 47 (4): 76-84.

[3] Wang, W., Xu, Y., and Khanna, M. 2011. "A Survey on the Communication Architectures in Smart Grid." Computer Networks 55 (15): 3604-29. 
[4] Ito, Y., Yang, Z., and Hirofumi, A. 2009. "A Control Method for Small-Scale DC Power Systems Including Distributed Generators." Electrical Engineering in Japan 167 (2): 1236-42.

[5] Kurohane, K., Senjyu, T., Yona, A., Urasaki, N., Goya, T., and Funabashi, T. 2010. "A Hybrid Smart ac/dc Power System." IEEE Transactions on Smart Grid 1 (2): 199-204.

[6] Yamauchi, H., Kina, M., Kurohane, K., Uchida, K., Yona, A., and Senjyu, T. 2011. "Operation Principle of Multiple DC Smart Grids." In Proceedings of the 2011 IEEE Ninth International Conference on PEDS (Power Electronics and Drive Systems), 304-9.

[7] Nassor, T., Ziadi, Z., Yona, A., Senjyu, T., and Abdel-Akher, M. 2012. "Comprehensive Analysis of DC Smart Grid Operation." In Proceedings of the 2012 IEEE International PECon (Conference on Power and Energy), 880-5.

[8] Nassor, T. S., Kina, M., Senjyu, T., Yona, A., and Funabashi, T. 2012. "Operation of Multi DC Smart Grids Based on Renewable Energy Sources and Protection of DC Transmission Line." International Journal of Emerging Electric Power Systems 13 (3): 1553-779.

[9] Balamurugan, T., and Manoharam, S. 2012. "Fuzzy Controller Design Using Soft Switching Boost Converter for MPPT in Hybrid System." International Journal of Soft Computing and Engineering 2 (5): 87-94.

[10] Yong, Y., Xing, L., Shen, G., Zude, Z., and Jihong, W. 2008. "A Battery Charging Control Strategy for Renewable Energy Generation Systems." In Proceedings of the WCE (World Congress on Engineering), 356-61.

[11] Neeraj, S., Bohn, T., Duoba, M., Lohse-Busch, H., and Sharer, P. 2007. 'PHEV 'All Electric Range' and Fuel Economy in Charge Sustaining Mode for Low SOC Operation of the JCS VL41M Li-ion Battery Using Battery HIL.” Argonne National Laboratory. Accessed July $\quad 04, \quad 2015$. http://www.transportation.anl.gov/pdfs/HV/463.pdf.

[12] Hu, W., Chen, Z., Wang, Y., and Wang, Z. 2008. "Wind Power Fluctuations Mitigation by DC-Link Voltage Control of Variable Speed Wind Turbines." In Proceedings of the 43rd International UPEC (Universities Power Engineering Conference), 1-5.

[13] Haque, M., Muttaqi, K., and Negnevitsky, M. 2008. "Control of a Stand Alone Variable Speed Wind Turbine with a Permanent Magnet Synchronous Generator." In Proceedings of the Power and Energy Society General Meeting-Conversion and Delivery of Electrical Energy in the 21st Century, 1-9.
[14] Rosyadi, M., Muyeen, S. M., Takahashi, R., and Tamura, J. 2012. “A Design Fuzzy Logic Controller for a Permanent Magnet Wind Generator to Enhance the Dynamic Stability of Wind Farms." Applied Sciences 2 (5): 780-800.

[15] Wu, F., Zhang, X. P., and Ju, P. 2009. "Small Signal Stability Analysis and Control of the Wind Turbine with the Direct-Drive Permanent Magnet Generator Integrated to the Grid." Electric Power Systems Research 79 (12): 1661-7.

[16] Hansen, A. D., and Michalke, G. 2008. "Modelling and Control of Variable-Speed Multi-pole Permanent Magnet Synchronous Generator Wind Turbine." Wind Energy 11 (5): 537-54.

[17] Senjyu, T., Sakamoto, R., Urasaki, N., Funabashi, T., Fujita, H., and Sekine, H. 2006. "Output Power Leveling of Wind Turbine Generator for All Operating Regions by Pitch Angle Control." IEEE Transactions on Energy Conversion 21 (2): 467-75.

[18] Rahmani, R., Seyedmahmoudian, M., Mekhilef, S., and Yusof, R. 2013. "Implementation of Fuzzy Logic Maximum Power Point Tracking Controller for Photovoltaic System." Journal of Electrical and Electronics Engineering 10 (3): 209-18.

[19] Chung, H. H., Tse, K. K., Hui, S., Mok, C. M., and Ho, M. T. 2003. "A Novel Maximum Power Point Tracking Technique for Solar Panels Using a Sepic or Cuk Converter." IEEE Transactions on Power Electronics 18 (3): 717-24.

[20] Walker, G. 2001. "Evaluating MPPT Converter Topologies Using a MATLAB PV Model.” Journal of Electrical and Electronics Engineering 21 (1): 49-56.

[21] Agarwal, V., and Vishwakarma, A. 2009. "A Modified Method for Maximum Power Point Tracking of PV Cell." Journal of Electrical and Electronic Systems Research 2 (June): 2161-5.

[22] Tremblay, O., Dessaint, L. A., and Dekkiche, A. I. 2007. "A Generic Battery Model for the Dynamic Simulation of Hybrid Electric Vehicles." In Proceedings of the VPPC (Vehicle Power and Propulsion Conference), 284-9.

[23] Pang, S., Farrell, J., Du, J., and Barth, M. 2001. "Battery State-of-Charge Estimation." In Proceedings of the American Control Conference, 1644-9.

[24] Li, X., and Bhat, A. K. S. 2008. "AC Equivalent Circuit Analysis for High-Frequency Isolated Dual-Bridge Series Resonant DC/DC Converter." In Proceedings of the PESC (Power Electronics Specialists Conference), 238-44.

[25] Li, X., and Bhat, A. K. S. 2010. "Analysis and Design of High-Frequency Isolated Dual-Bridge Series Resonant DC/DC Converter." IEEE Transactions on Power Electronics 25 (4): 850-62. 
[26] Krismer, F., Round, S., and Kolar, J. 2006. "Performance Optimization of a High Current Dual Active Bridge with a Wide Operating Voltage Range." In Proceedings of the 37th IEEE PESC (Power Electronics Specialists Conference), 1-7.
[27] Biela, J., Aggeler, D., Inoue, S., Akagi, H., and Kolar, J. 2008. "Bi-directional Isolated DC-DC Converter for Next-Generation Power Distribution Comparison of Converters Using Si and SiC Devices." The Institute of Electrical Engineers of Japan 128 (7): 1-10. 